\title{
Opportunities and Threats of Cloud Computing in HealthCare
}

\author{
Abdul Manan \\ IT Department, University of Gujrat \\ Gujrat, Pakistan
}

\author{
Imran Ashraf \\ Lecturer IT Department \\ University of the Punjab, Pakistan
}

\begin{abstract}
With its on demand services model, cloud computing is making its way in every field and healthcare is no exception to it. Healthcare is readily moving its way to adaptation of cloud computing. This shift is to enjoy clouds services of minimized cost, effective use of resources and maximized availability of services. However, like other fields healthcare is hesitant to embrace the cloud computing environment due to concerns of data privacy, availability and data integrity. This paper provides a brief overview of opportunities and threats of cloud computing (CC) in healthcare industry. The major aim of this review paper is to find out the current and future opportunities and threats faced by the cloud services providers in healthcare.
\end{abstract}

\section{General Terms}

Cloud Computing (CC), Health Information Technology (HIT), Healthcare Industry (HCI)

\section{Keywords}

Cloud Computing (CC), Health Information Technology (HIT), Cloud Services Provider, Healthcare Industry (HCI), Privacy, Data Availability, Data Integrity

\section{INTRODUCTION}

Last few decades observed a huge paradigm shift in the field of information technology. Organizations shift from manual systems to computerized information systems. Many fields made this shift and healthcare is no exception. Today, the chief focus of healthcare service is to minimize operational cost and effective utilization of latest technologies as well as to enhance the healthcare services especially [1-3]. Health information Technology (HIT) "is a set of technologies that are used to convey and manage health information for use by all the groups which have interest in health as well as in health care" [4].

"The cloud is a large collection of interconnected computers that provides on-demand, self-service, broad network access, resource pooling, rapid elasticity, and measured service" [5]. Cloud Computing (CC) has many benefits over traditional information systems. Firstly it enables users' for accessing their own data as well as services through Cloud Computing (CC) at any time wherever they are. Due to this opportunity, cloud computing store and maintain databases in the effective way. Pay-as-use is the most important benefit of cloud computing. It enables users to pay only for what they have to use [40]. One of the major advantages is that services on cloud are updated regularly by the service provider. This makes user unworried about the updating of services or applications [19].

The advantages of pay as use, automatic updating, no need of establishing own infrastructure and efficient maintenance of databases makes CC widely used in healthcare organizations. Instead of managing as well as maintaining of complex Health Information Technology (HIT) systems, it is shifting its burden by getting services from the Cloud service providers $[7,8]$. According to the [6] "it is expected that about $80 \%$ of the today's organizations will be shifted on cloud till 2020". In spite of these advantageous benefits organizations using cloud computing services are facing a lot of challenges and risks. The main challenge is extensive security necessities by the healthcare cloud services providers. Privacy is also one of the major issues of cloud computing in e-Health [10-12].

In what follows, in section two is the background of current Healthcare Information Technology (HIT) systems. E-Health Cloud Challenges are present in third section. In fourth section, we discuss opportunities and threats faced by the current cloud service providers. In the end conclusions as well as future work is described.

\section{BACKGROUND}

All The data or information is of the chief concerns for the organizations especially in healthcare as it needs to be available and secure from unauthorized access. The patient's data was stored on manual files and kept them in safes under physical locks in the near past. Data was secured by taking measures of physical security. After the advancement in computer field, organizations shifted from traditional manual systems to computer based data storage systems. These computer based information system stored data on hard drives, tape drives and backup were regularly taken for recovery of data in case of emergency. Data was secure and efficient as well as effective to manage and retrieve by using these automated healthcare information systems. This paradigm shift forced health organizations to rely totally on computer based information systems [14].

Every organization develops infrastructure of computer based information systems according to its own requirements. In healthcare these systems are called health information technology (HIT). These standalone HIT systems has changed the organizations totally by providing complete and integrated solutions for an organization [13]. Due to HIT, reactive and passive systems are transforming into proactive as well as interactive systems in sense of quality of healthcare services [15-18]. In HIT data is stored on server machines. Major issue of HIT is that every organization has to establish its own infrastructure which requires installation, maintenance, operation costs. Moreover, data is stored on single centralized site which raised the issues of availability, increased communication cost, single source bottleneck etc [41]. So, organizations shifted on distributed databases to overcome issues of HIT. With distribution comes the concept of cloud computing which is cheap, easy to use and easy to up or down grade. However, this emerging technology has many issues 
which need to be taken care of like privacy, availability, legitimate access, integrity etc.

\section{CHALLENGES OF E-HEALTH CLOUD}

No doubt, e-Health Cloud delivers a lot of benefits in the industry of health care, but unfortunately it receive a number of challenges in HIT as well as in cloud computing. Processing and storing of sensitive medical data of patients is a major challenge. The following section describes the issues [20, 21-32] and challenges of e-Heath Cloud and their proposed solutions.

\subsection{Data/Service Reliability}

Cloud service providers need to ensure excellent reliability of services over the cloud especially in healthcare industry. Healthcare need data in the right form as well as cloud services. Illegitimate changes in data and errors in data are not acceptable. So cloud must provide data and services without any error.

\subsection{Data Management}

E-health cloud needs to provide storage of millions of patients. Medical specialist accesses this sensitive data from different location at the same time. There are different views of data like HD graphics, 3D and audio and video data. In order to manage this data efficiently and provide it when desired, fault tolerant systems/services need to be assured.

\subsection{Flexibility}

According to the needs of different healthcare providers, eHealth Cloud Service provider should be capable to serve accordingly. The services provided by cloud should also be very flexible so that services can be configured according to user requirements. Additionally, adding new services as need should be accommodated.

\subsection{Availability}

The most important requirement for any healthcare providers is the consistent availability of the services from e-Health Cloud. Healthcare providers cannot continue their functions without availability of services and patient's sensitive data. This is why these services should be consistently available without any disturbances. The main reasons for failure of Cloud services may include network failure, software and hardware failure, or security attacks and natural disasters [33]. E-Health Cloud should be proactive and ensure continuity of service in effective and efficient way. If backend up gradation is required then services for the healthcare should not be interrupted.

\subsection{Security}

Could Service providers store data, of patients from different healthcare organizations? There is need of strong access control and authorization mechanism to secure this huge and sensitive data. The security standards should be implemented so that sensitive data can only be accessible to right organization. E-healthcare service providers can only be shifted on cloud if they are guaranteed of their desired security. So, policies and standard as organizations wants should be properly implemented by the cloud services provider [34].

\subsection{Privacy}

Many healthcare organizations are hesitant to shift to cloud computing services due to privacy concerns [35]. For eHealthcare systems, Privacy is one of the major alarms because of sensitivity of patient's data [36, 37]. Due to sensitivity of patient records cloud is facing serious privacy issues. Recently United States of America (USA) Intelligence agencies recorded the sensitive information of German chancellor. Now organizations are worried about privacy issues.

\section{DISCUSSIONS}

No doubt, e-Health Cloud is providing opportunities to healthcare industry but unfortunately it is still facing some of the serious challenges. Privacy and security are the major issues faced by the healthcare organizations. Cloud services providers are trying their best to provide services on minimal cost and in effective and efficient way [38]. Important benefits provided by the E-Health cloud include

1. Cost minimization due to acquiring on demand services by cloud instead of establishing their own infrastructure.

2. Sharing of Medical records of patients with other organizations and specialists around the world.

3. Minimized maintenance and administration cost of operations

4. Maximized health information in sense of availability as well as flexibility

From all above benefits, cloud computing looks best option for healthcare industry to adopt, but security and privacy are the two main hurdles for future. Although current service providers claim to provide demanded security and privacy, yet implementation of security policies as needed by healthcare is a task much complex to implement. To prevent patient's data from unauthorized access is the major concern for healthcare industry. Other than security and privacy hierarchy of Authorization and access control are also complex tasks. Unluckily, there are lack of guidelines and standards to tackle these needed issues and at the moment cloud computing is unable to provide services at their best [39].

\begin{tabular}{|c|c|}
\hline Opportunities & Challenges \\
\hline $\begin{array}{l}\text { - No administrative } \\
\text { and maintenance } \\
\text { costs } \\
\text { - Efficient storage }\end{array}$ & $\begin{array}{ll}\text { Reduced cost may } \\
\text { result in trade off } \\
\text { in quality of } \\
\text { service } \\
\text { Continued } \\
\text { availability even } \\
\text { during break } \\
\text { downs and } \\
\text { maintenance } \\
\text { Unavailability due } \\
\text { to network, } \\
\text { software and } \\
\text { hardware failures } \\
\text { Lack of } \\
\text { administering } \\
\text { power may result } \\
\text { in absence of } \\
\text { proper security } \\
\text { procedures } \\
\text { Diversified data } \\
\text { like audio, video, } \\
\text { 3D graphics need } \\
\text { special storage } \\
\text { Changes or errors } \\
\text { in data can cause } \\
\text { serious problems } \\
\text { Access control } \\
\text { strategies to ensure } \\
\text { privacy } \\
\text { Data integrity and } \\
\text { security to protect } \\
\text { sensitive data }\end{array}$ \\
\hline
\end{tabular}




\begin{tabular}{|l|l|}
\hline & $\begin{array}{l}\text { Flexibility needed } \\
\text { for configuration of } \\
\text { diversified nature } \\
\text { of health care } \\
\text { service }\end{array}$ \\
& $\begin{array}{l}\text { In case of system } \\
\text { crashes, data } \\
\text { recovery in cloud } \\
\text { has very serious } \\
\text { problems }\end{array}$ \\
& \\
\hline $\begin{array}{l}\text { Backup and } \\
\text { recovery }\end{array}$ & \\
\hline
\end{tabular}

\section{CONCLUSION AND FUTURE WORK}

This paper presents review on the opportunities and challenges faced by cloud service providers in healthcare industry. Health information Technology (HIT) needs to minimize their huge cost which is spent on implementation and maintenance of HIT. But they also need to handle risk of unavailability of services, loss of data and data security. No doubt cloud computing is very viable solution for e-healthcare problem but then they need to focus on data security, privacy, data ownership, trust and legitimate access of patients sensitive data.

Since healthcare industry is too large and requires services in effective and ideal manner. Current researches and proposed solutions are not enough to handle these problems, so researchers need to devise new techniques to manage these issues of healthcare. With the advent of new techniques in cloud computing, improved quality of services can be provide at minimized cost, maximized availability of services and with better patient care.

\section{REFERENCES}

[1] Goldschmidt, P.G. HIT and MIS: Implications of health information technology and medical information systems. Commun. ACM 2005, 48, 69-74.

[2] Davidson, E.; Heslinga, D. Bridging the IT adoption gap for small physician practices: An action research study on electronic health records. Inf. Syst. Manag. 2006, 24, $15-28$.

[3] Klein, R. An empirical examination of patient-physician portal acceptance. Eur. J. Inf. Syst. 2007, 16, 751-761.

[4] D. Blumenthal and J. P. Glaser, "Information Technology Comes to Medicine," New England Journal of Medicine356, no. 4 (2007): 2527-2534, at 2527

[5] NIST SP 800-145, “A NISTDEFINITION OF CLOUDCOMPUTING”, http://csrc.nist.gov/publications/nistpubs/800-145/sp800145.pdf, accessed on 3/8/2012.

[6] Kuttikrishnan, D. (2011). Cloud Computing: The road ahead.Retrieved from http://www.datamation.com/cloudcomputing/cloud-computing-the-road-ahead-1.html

[7] Teng, C.C.; Mitchell, J.; Walker, C. A Medical Image Archive Solution in the Cloud. In Proceedings of the 2010 IEEE International Conference on Software Engineering and Service Sciences (ICSESS), Beijing, China, 16-18 July 2010; pp. 431-434.

[8] Cloud Computing: Clear Benefits: The Emerging Role of Cloud Computing in Healthcare Information Systems. Available online: http://www.techrepublic.com/whitepapers/cloudcomputing-clear-benefits-the-emerging-role-of-cloudcomputing-in-healthcare-information-systems/2384337 (accessed on 28 June 2012)

[9] Chow, R.; Golle, P.; Jakobsson, M.; Shi, E.; Staddon, J.; Masuoka, R.; Molina, J. Controlling Data in the Cloud Outsourcing Computation without Outsourcing Control. In Proceedings of the 2009 ACM Workshop on Cloud Computing Security, Chicago, IL, USA, 9-13 November 2009; pp. 85-90.

[10] Pearson, S. Taking Account of Privacy when Designing Cloud Computing Services. In Proceedings of the ICSE Workshop on Software Engineering Challenges of Cloud Computing at CLOUD'09, Washington, DC, USA, 23 May 2009; pp. 44-52.

[11] Goldman, J.; Hudson, Z. Virtually exposed: Privacy and e-health. Health Aff. 2000, 19, 140-148.

[12] Kelly, E.P.; Unsal, F. Health information privacy and ehealthcare. Int. J. Healthc. Technol.Manag. 2002, 4, $41-52$.

[13] Lenz, R.; Reichert, M. IT support for healthcare processes-Premises, challenges, perspectives.DataKnowl. Eng. 2006, 61, 39-58.

[14] J Gen Intern Med. Apr 2008; 23(4): 495-499.Published online Mar 29, 2008. doi: 10.1007/s11606-007-0394-y,

[15] Saranummi, N. In the spotlight: Health information systems. IEEE Rev. Biomed. Eng. 2008, 1, 15-17.

[16] Saranummi, N. In the spotlight: Health information systems-PHR and value based healthcare.IEEE Rev. Biomed. Eng. 2009, 2, 15-17.

[17] Saranummi, N. In the spotlight: Health information systems-MainstreamingmHealth. IEEE Rev.Biomed. Eng. 2011, 4, 17-19.

[18] Vasilakos, A.V.; Lisetti, C. Special section on affective and pervasive computing for healthcare.IEEE Trans. Inf. Technol. Biomed. 2010, 14, 183-359

[19] e-Health Cloud: Opportunities and ChallengesEmanAbuKhousa, Nader Mohamed * and Jameela Al-JaroodFuture Internet 2012, 4, 621-645; doi:10.3390/fi4030621

[20] Lohr, H.; Sadeghi, A.; Winandy, M. Securing the EHealth Cloud. In Proceedings of the 1st ACM International Health Informatics Symposium (IHI 2010), Arlington, VA, USA, 11-12 November 2010; pp. 220229

[21] Commonwealth Secretariat. Progress report. Available online:

http://www.thecommonwealth.org/files/189921/FileNam e/HealthProgressReports-E-Health.pdf (accessed on 28 June 2012).

[22] Momtahan, L.; Lloyd, S.; Simpson, A. Switched Lightpaths for E-Health Applications: Issues and Challenges. In Proceedings of the Twentieth IEEE International Symposium Computer-Based Medical Systems (CBMS'07), Maribor, Slovenia, 20-22 June 2007; pp. 459-464.

[23] Agrawal, D.; Abbadi, A.; Antony, S.; Das, S. Data Management Challenges in Cloud Computing 
Infrastructures. In Proceedings of the 6th International Workshop on Databases in Networked Information Systems (DNIS 2010), Aizu-Wakamatsu, Japan, 29-31 March 2010.

[24] Hasan, J. Effective telemedicine project in Bangladesh: Special focus on diabetes health care delivery in a tertiary care in Bangladesh. Telemat. Inform. 2012, 29, 211-218. Future Internet 2012, 4643

[25] Rayport, J.F.; Heyward, A. Envisioning the Cloud: The Next Computing Paradigm. A MarketspaceNext Point of View. Available online: $\mathrm{http} / / /$ marketspacenext.com/inthemedia/envisioning-thecloud/ (accessed on 28 June 2012).

[26] Introduction to Cloud Computing Architecture. Sun Microsystems: Santa Clara, CA, USA, 2009.

[27] Varia, J. Cloud Architectures. Available online: http://aws.amazon.com/articles/1632?_encoding=UTF8\& jiveRedirect=1 (accessed on 28 June 2012).

[28] Hosseini, A.; Sommerville, I.; Sriram, I. Research Challenges for Enterprise Cloud Computing. Available online: http://arxiv.org/abs/1001.3257 (accessed on 28 June 2012)

[29] Mei, L.; Chan, W.K.; Tse, T.H. A Tale of Clouds: Paradigm Comparisons and Some Thoughts on Research Issues. In Proceedings of the Asia-Pacific Services Computing Conference (APSCC'08), Yilan, Taiwan, 912 December 2008; pp. 464-469.

[30] Armbrust, M.; Fox, A.; Griffith, R.; Joseph, A.; Katz, R.; Konwinski, A.; Lee, G.; Patterson, D.; Rabkin, A.; Stoica, I.; Zaharia, M. Above the Clouds: A Berkeley View of Cloud Computing.Available online: http://inst.cs.berkeley.edu/ cs10/fa10/lec/20/2010-11-10CS10-L20-AF-Cloud-Computing.pdf (accessed on 29 June).

[31] Sriram, I.; Khajeh-Hosseini, A. Research Agenda in Cloud Technologies. In Proceedings of the 1st ACM Symposium on Cloud Computing, SOCC 2010, Indianapolis, IN, USA, 10-11 June 2010.
[32] Youseff, L.; Butrico, M.; da Silva, D. Toward a Unified Ontology of Cloud Computing. In Proceedings of the Grid Computing Environments Workshop (GCE'08). Austin, TX, USA, 12-6November 2008; pp. $1-10$.

[33] Leavitt, N. Is cloud computing really ready for prime time? Computer 2009, 42, 15-20

[34] Chow, R.; Golle, P.; Jakobsson, M.; Shi, E.; Staddon, J.; Masuoka, R.; Molina, J. Controlling Data in the Cloud: Outsourcing Computation without Outsourcing Control. In Proceedings of the 2009 ACM Workshop on Cloud Computing Security, Chicago, IL, USA, 9-13 November 2009; pp. 85-90.

[35] Pearson, S. Taking Account of Privacy when Designing Cloud Computing Services. In Proceedings of the ICSE Workshop on Software Engineering Challenges of Cloud Computing at CLOUD'09, Washington, DC, USA, 23 May 2009; pp. 44-52.

[36] Goldman, J.; Hudson, Z. Virtually exposed: Privacy and e-health. Health Aff. 2000, 19, 140-148.

[37] Kelly, E.P.; Unsal, F. Health information privacy and ehealthcare. Int. J. Healthc. Technol.Manag. 2002, 4, 41-52.

[38] Flaaen, Stephen. "Information Security and the Cloud." (2012).

[39] e-Health Cloud: Opportunities and ChallengesEmanAbuKhousa, Nader Mohamed * and Jameela Al-JaroodFuture Internet 2012，4，621-645; doi:10.3390/fi4030621

[40] Petersen, Laura A., LeChauncy D. Woodard, Tracy Urech, Christina Daw, and Supicha Sookanan. "Does pay-for-performance improve the quality of health care?" Annals of internal medicine 145, no. 4 (2006): 265-272.

[41] Ashraf,I. Shahzed A, Khokhar. "Impact of Data Distribution on Response Time in Telecom Databases". International Journal of Engineering Research and Applications. Vol. 3, Issue 6, Nov-Dec 2013, pp.404-412 